\title{
Conformational States of the Spiropyran Molecule
}

\author{
Olha Kovalenko, ${ }^{1}$ Petro Kondratenko, ${ }^{2}$ and Yuriy Lopatkin ${ }^{1}$ \\ ${ }^{1}$ Department of General and Theoretical Physics, Sumy State University, 2 Rimsky-Korsakov Street, Sumy 40007, Ukraine \\ ${ }^{2}$ Department of Theoretical Physics, Aerospace Institute, National Aviation University, 1 Kosmonavt Komarov Prospekt, \\ Kiev 03680, Ukraine \\ Correspondence should be addressed to Olha Kovalenko; olya.sumy.ua@gmail.com
}

Received 9 April 2015; Revised 18 June 2015; Accepted 21 June 2015

Academic Editor: Mark van Der Auweraer

Copyright (c) 2015 Olha Kovalenko et al. This is an open access article distributed under the Creative Commons Attribution License, which permits unrestricted use, distribution, and reproduction in any medium, provided the original work is properly cited.

The form of the potential surface of the ground state was investigated on the basis of indoline spiropyran. As a result of this work the rotamers of an open-ring form of the spiropyran molecule were discovered, and the existence of the most probable rotamers was justified. The 3D potential surface of the ground state of the spiropyran molecule was built. The route of the isomerization of the molecule was discovered and values of barriers for this reaction were found. The part of the isomerization route that is responsible for changing the hybridization of spiroatom from $\mathrm{sp}^{3}$ to $\mathrm{sp}^{2}$ was found.

\section{Introduction}

To date the creation of the controlled and steady state photochromic systems is one of the important areas in organic chemistry. The interest in photochromic compounds is associated with the broad spectra of possible applications. The development of the photochromic materials is a relevant field of scientific researches. It is related to the production of the perspective materials which are used for data storing technologies and reproducing information, colour filters production, photochromic lenses production, optical switches, and various components of molecular electronics. This is possible due to the fact that photochromic compounds are capable of changing their structure reversibly by activating electromagnetic radiation. As a consequence the electronic absorption spectrum and other physicochemical characteristics are changed [1-5].

Photochromic spirocyclic compounds find many possible applications, and therefore broad requirements are presented to their properties. Hence, the study of the behavior of molecular spirocyclic systems under the influence of electromagnetic radiation is an important and urgent task. Solution of this task allows understanding correlation between molecular structure of the substance and its spectral-kinetic characteristics in detail. By turn, it points to the route of transformation of the materials structure to obtain the desired properties from them [6].

One of the most prospective and studied classes of organic photochromic compounds is spiropyrans. The photochromic properties of spiropyrans are determined by the photoinduced cleavage of the bond in the benzopyrene fragment. This cleavage leads to the appearance of the open-ring merocyanine form $[7,8]$. Tangible difference in colour of cyclic and merocyanine forms of the molecule is one of the main advantages of spiropyrans. In the first case the molecule is colourless, and in the second case there is an intense frequently dark colour $[9,10]$. Besides, the distinguishing feature of spiropyrans is good spectral discernibility of the isomers and the ability of "setting" the photochromic characteristics by changing the structure. Transition between isomers can be realized with the light [11]. In addition, the absence of $\pi$-conjugation in the spiropyran molecules and its presence in merocyanine molecules make these molecules prospective for creation molecular components of the computer engineering such as switches and memory cells.

Plenty of scientific works are devoted to the investigation of the spiropyran molecule [12-27]. It is necessary to say that at such interest in spiropyrans during the half a century there is still no clear opinion about the mechanism of spiropyranmerocyanine switching. Different schemes of such transition 


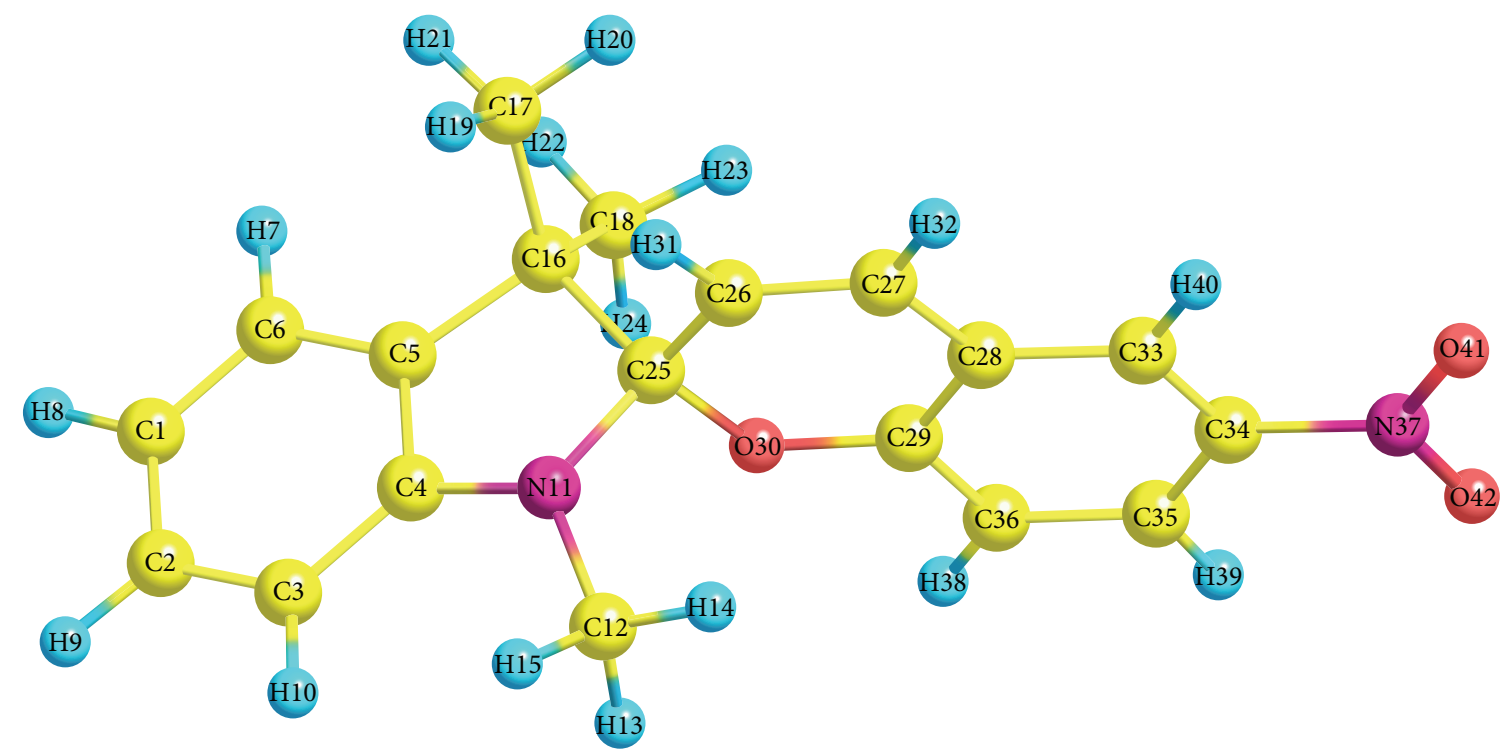

FIGURE 1: General structure of the spiropyran.

are offered. Probably, the authors of work [17] are the closest to a solution, but there is still a feeling that a definitive answer has not been received yet.

Conformational transitions between rotamers have not been fully investigated, the routes of the transition processes of the spiropyran molecule between "closed" and "open" forms have not been studied in detail, and the influence of these processes on the electronic spectra of the spiropyran molecule has not been determined. These points defined a trend of the research.

Thus, the purpose of this study was as follows.

(1) The investigation of the isomers existence of the "open" form of the molecule relative to $\mathrm{C}(27)-\mathrm{C}(28)$ and $\mathrm{C}(26)-\mathrm{C}(27)$ bonds by constructing potential curves and determination of the values of barriers between them.

(2) The investigation of the routes of ring-closing processes of rotamers; finding the dependence between the bond energy of the molecule and the length of the bond between $\mathrm{C}_{\text {spiro }}-\mathrm{O}$ atoms in the given molecules.

\section{Object and Methods}

Spiropyran shows thermochromic properties and in solution it is in equilibrium with the open form at room temperature. In Figure 1 the general structure of spiropyran is presented.

Nonplanar indoline and benzopyrene fragments are located in a molecule approximately orthogonal to each other. A dihedral angle between planes $\mathrm{O}(30)-\mathrm{C}(25)-\mathrm{C}(26)$ of the benzopyrene and $\mathrm{N}(11)-\mathrm{C}(25)-\mathrm{C}(26)$ of the indoline cycles at the spiroatom $\mathrm{C}(25)$ is $86.3^{\circ}$. The length of the bond between $\mathrm{C}_{\text {spiro }}-\mathrm{O}$ atoms in the "closed" molecule is $1.424 \AA$. A geometric optimization for the merocyanine molecule (open form of the spiropyran) had the same settings as a closed form. The distance between $\mathrm{C}_{\text {spiro }}$ and $\mathrm{O}$ atoms is $4.423 \AA$ [28]. This molecule is shown in Figure 2.

A calculation of the molecule was realized with AM1, PM3, and MNDO/d methods [29, 30]. But the preference was given to $\mathrm{MNDO} / \mathrm{d}$. In this case, the choice of $\mathrm{MNDO} / \mathrm{d}$ method was conditioned on the fact that it provides the best reproduction of the experimental values of energy $E$ of an electronic system on the occupied molecular orbitals (OMO) which are known.

It is known that semiempirical and nonempirical methods do not differ fundamentally in the view of the approach to the solution of molecular Schrödinger equation. The same general scheme of calculation is used for the semiempirical methods as for the ab initio methods [31]. The difference is that each stage of calculation is greatly simplified.

The precision of calculation of some characteristics of molecules with the semiempirical methods may be even not lower than with the ab initio methods for separate classes of chemical compounds (mainly organic). This is due to the fact that the parameterization of semiempirical methods is realized on the experimental values of certain characteristics of real materials. Naturally, these values are reproduced with high precision [32]. But even if the semiempirical methods often yield to ab initio or DFT methods, they can be useful in many situations, including the exposure and understanding of the properties of the compounds and trends of processes evolution and also therein a qualitative understanding of the properties is enough [33]. Semiempirical calculations are the most successful ones in the description of organic chemistry, where only a few elements are widely used and molecules are medium-sized.

In our case we came to the fact that relative changes are important for us, not absolute values. In addition, preliminary methods were approved on the already known experimental results. 


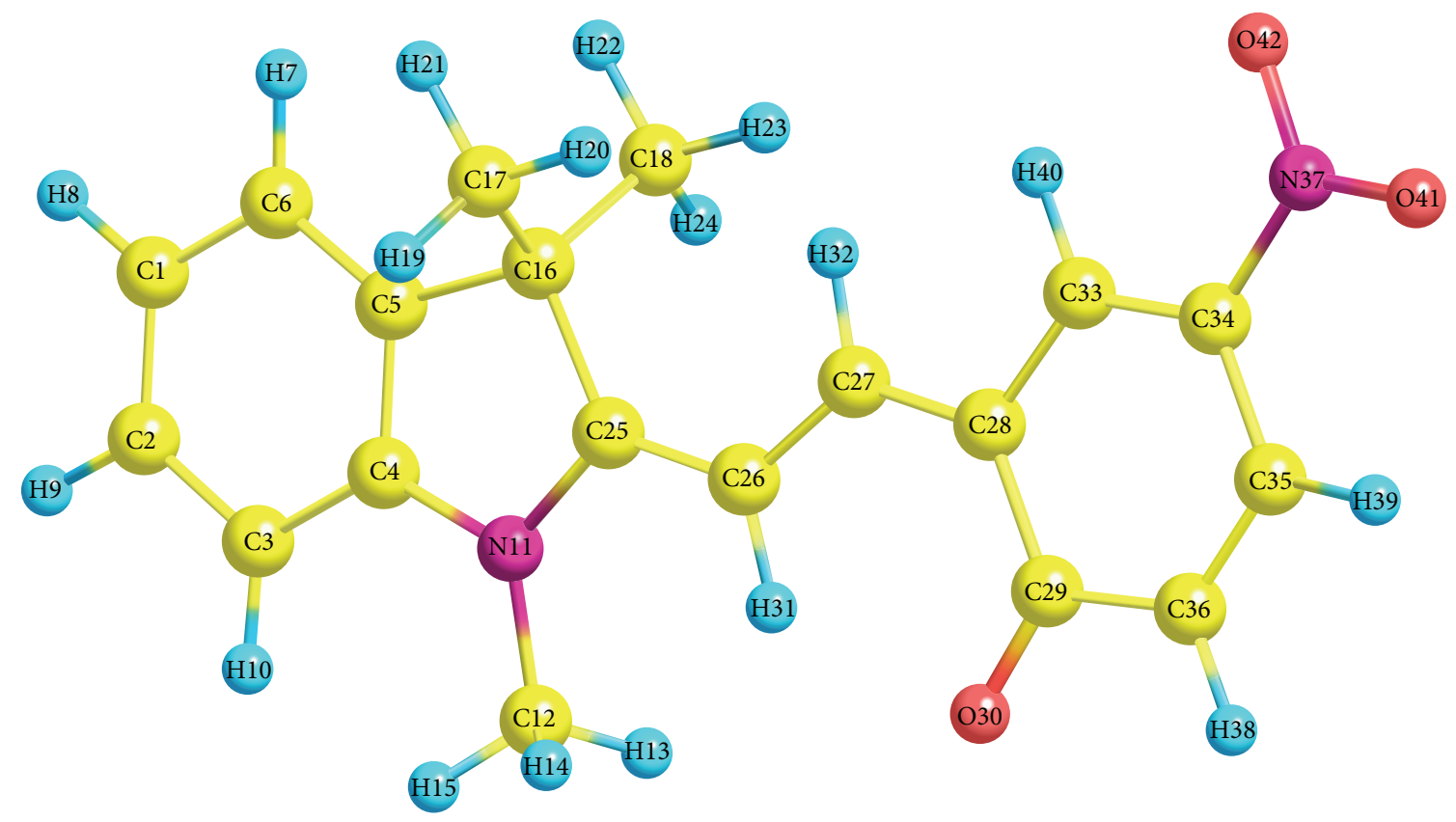

FIgURE 2: General structure of the merocyanine.

In this work it was necessary to scan the distance between $\mathrm{C}_{\text {spiro }}-\mathrm{O}$ atoms and at the same time there was a need to optimize the geometric structure of the molecule. Toward this end, software product MOPAC-12 was used.

MOPAC-12 allows optimizing the structure and at that it keeps necessary distance between atoms.

Molecular Modeling System HyperChem (Release 8.0.6. for Windows) was used for calculation of absorption spectra.

\section{Results and Discussion}

It is known that under the influence of light the spiropyran molecule turns into the merocyanine with high quantum yield. Similarly, the merocyanine molecule grows into the spiropyran molecule under light or heat influence. So, we have a cyclic process of molecule transformations. During the transformation of spiropyran molecule to merocyanine molecule and vice versa the intermediate process takes place. This process shows itself in the optical absorption spectra and is called $\mathrm{X}$ isomer $[34,35]$.

Considering the structure of the spiropyran molecule we see that it consists of two noninteracting $\pi$-electron systems causing the presence of bands in the absorption spectrum of the spiropyran in the ultraviolet region of the spectrum. On the other hand, the merocyanine molecule has a single $\pi$ electron system which provides the molecule absorption in the visible spectrum.

Calculations of quantum transitions of these two types of molecules give the absorption spectrums which correlate with experimental data fully [36]. In Figures 3 and 4 bands positions of allowed (singlet-singlet) quantum transitions are marked in the bottom of the graphs by vertical lines. On the top of the graphs vertical lines mark permitted and prohibited (singlet-triplet) quantum transitions.

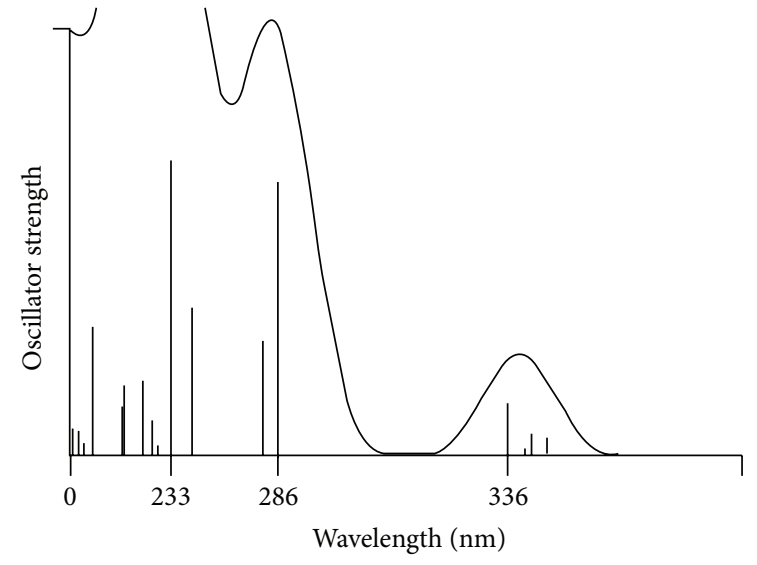

FIGURE 3: The absorption spectrum of the spiropyran.

The comparison of spiropyran and merocyanine structures shows that the bond between $\mathrm{C}(26)-\mathrm{C}(27)$ atoms in the first molecule has a cis-configuration and in the second transconfiguration. So, looking for the best way to convert one molecule to another, it is necessary to foresee the trans-cisisomerization relative to $\mathrm{C}(26)-\mathrm{C}(27)$ bond and then change the hybridization from $\mathrm{sp}^{3}$ to $\mathrm{sp}^{2}$ of nuclear orbitals of the spiroatom $\mathrm{C}(25)$. Besides, there is a need to find the optimal configuration of phenyl part of the molecule by the investigation of rotation of this fragment round the axis $\mathrm{C}(27)-\mathrm{C}(28)$. The result of this research is shown in Figure 3.

From Figure 5 it follows that both configurations have practically identical energies. Therefore, it can prove that they are equiprobable. The energetic barrier between these configurations is $1.6 \mathrm{eV}$. It makes rotamers stable (frequency factor of transition from one rotamer to another is 


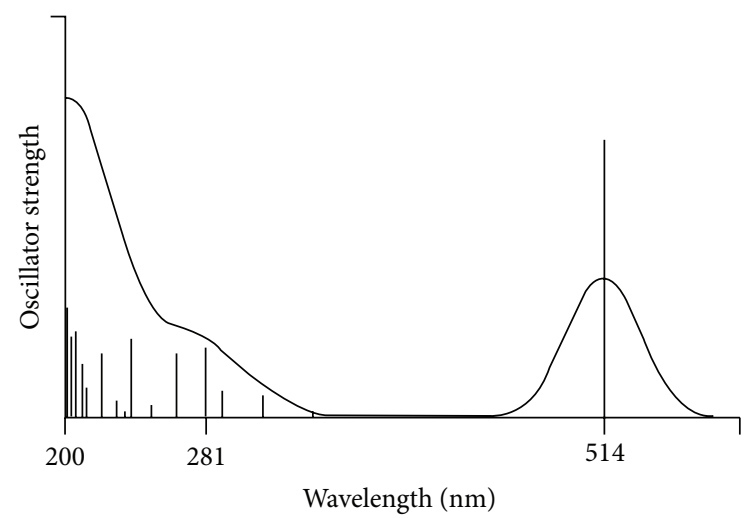

FIGURE 4: The absorption spectrum of the merocyanine.

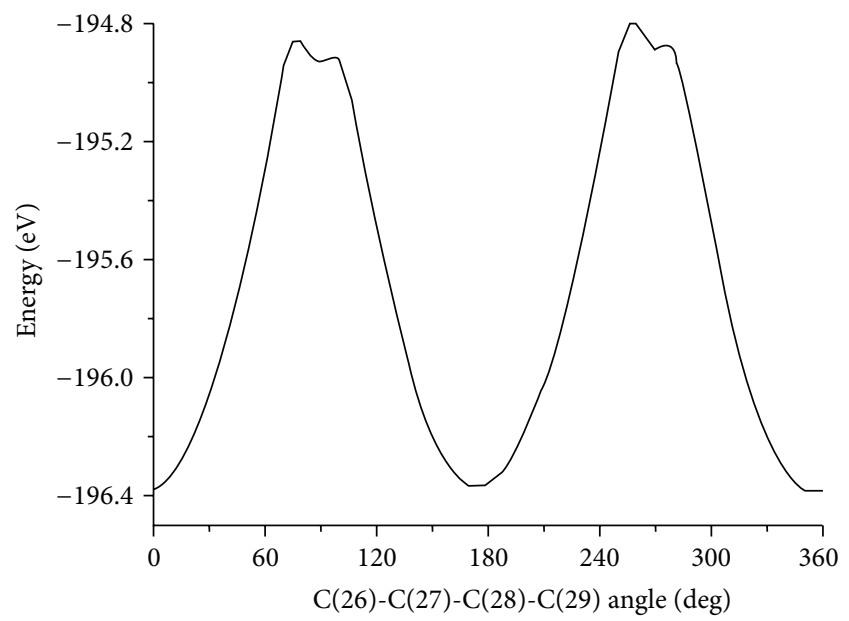

FIgURe 5: Potential barrier of the rotamer relative to $\mathrm{C}(27)-\mathrm{C}(28)$ bond.

$\left.0.24 \cdot 10^{-15} c^{-1}\right)$. However, further transformation of molecules will differ.

For returning the merocyanine molecule into the spiropyran shape the following is necessary.

(1) The structure of the merocyanine should be such that $\mathrm{C}(26)-\mathrm{C}(27)-\mathrm{C}(28)-\mathrm{C}(29)$ atoms form a cisconfiguration. In this case, the rotation around the $\mathrm{C}(26)-\mathrm{C}(27)$ bond will approach the oxygen atom to the spiroatom of carbon. Otherwise, approaching will not be observed.

(2) A rotation around $\mathrm{C}(26)-\mathrm{C}(27)$ bond on $180^{\circ}$ and around $\mathrm{C}_{\text {spiro }}-\mathrm{CH}$ bond on $90^{\circ}$ should be performed simultaneously. At the same time a special structure will be formed. It will transform to the spiropyran molecule along with $\mathrm{sp}^{2} \rightarrow \mathrm{sp}^{3}$ rehybridization. We cannot do it stepwise because there are steric prohibitions between the oxygen atom and substituents in the five-membered ring.

During the investigation of isomers which were obtained only by rotation around the $\mathrm{C}(26)-\mathrm{C}(27)$ bond in the "open" shape of the merocyanine molecule, calculation and analysis

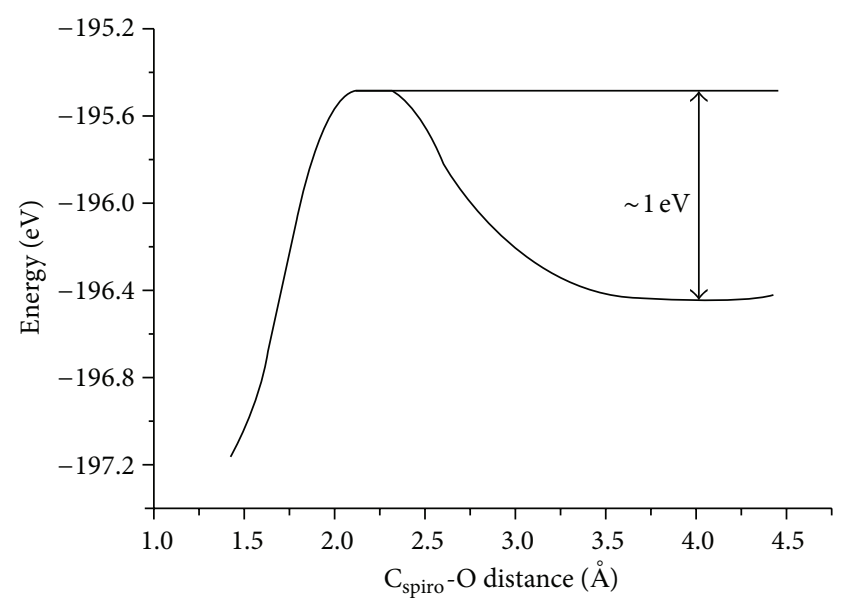

FIGURE 6: The dependence of energy from distance between $\mathrm{C}_{\text {spiro }}$ and $\mathrm{O}$ atoms for the merocyanine.

of potential barriers showed that both isomers are in potential wells. But the high altitude (about $70 \mathrm{eV}$ ) makes the existence of such isomerization reaction impossible. This height is caused by steric effects.

During the study of the ring-closing process the distance between the spiroatom and the oxygen atom was scanned from $4.423 \AA$ to $1.424 \AA$ with a step $0.2 \AA$. The bond was fixed and geometric optimization of other bonds was carried out at each step of the scanning. The graph of the ring-closing route for the merocyanine was built (Figure 6). After the result graph analyzing it is possible to define at what energy and at what distance between $\mathrm{C}_{\text {spiro }}$ and $\mathrm{O}$ atoms the chemical bond is broken.

Rehybridization in the spiropyran takes place by increasing the length of $\mathrm{C}_{\text {spiro }}$-O bond to $2.02 \AA$ (Figure 7). It is worth commenting the results that are shown in Figure 7 . When the distance between $\mathrm{C}_{\text {spiro }}$ and $\mathrm{O}$ atoms is over $2.5 \AA$ the value of $\mathrm{N}(11)-\mathrm{C}(25)-\mathrm{C}(26)$ angle is close to $120^{\circ}$. It points to $\mathrm{sp}^{2}$ hybridization of atomic orbitals of $\mathrm{C}_{\text {spiro }}$.

The decrease of the bond length from $2.5 \AA$ to $2 \AA$ leads to increase of the angle $\mathrm{N}(11)-\mathrm{C}(25)-\mathrm{C}(26)$. This is due to the steric interactions between the oxygen atom and the substituent. Further reducing of the distance between $\mathrm{C}_{\text {spiro }}$ and $\mathrm{O}$ atoms requires leaving the $\mathrm{C}(25)-\mathrm{C}(26)$ bond from the plane of molecule and as a consequence it causes the appearance of the rehybridization process from $\mathrm{sp}^{3}$ to $\mathrm{sp}^{2}$ of $\mathrm{C}_{\text {spiro }}$ atomic orbitals.

According to the research data it is possible to build 3D diagram (Figure 8). To construct this surface the scan of the distance between $\mathrm{C}_{\text {spiro }}$ and $\mathrm{O}$ atoms was conducted from $1.424 \AA$ to $4.423 \AA$ with step $0.2 \AA$. The calculation of potential barriers relative to the dihedral $C(26)-C(27)-C(28)-$ $\mathrm{C}(29)$ angle was realized at every step.

Figure 8 clearly shows the potential surfaces that describe the behavior of the merocyanine molecule in the ground state. However, the equilibrium state of the spiropyran molecule is closed with a barrier. Therefore, we have represented the shape of the potential surface in the form of 


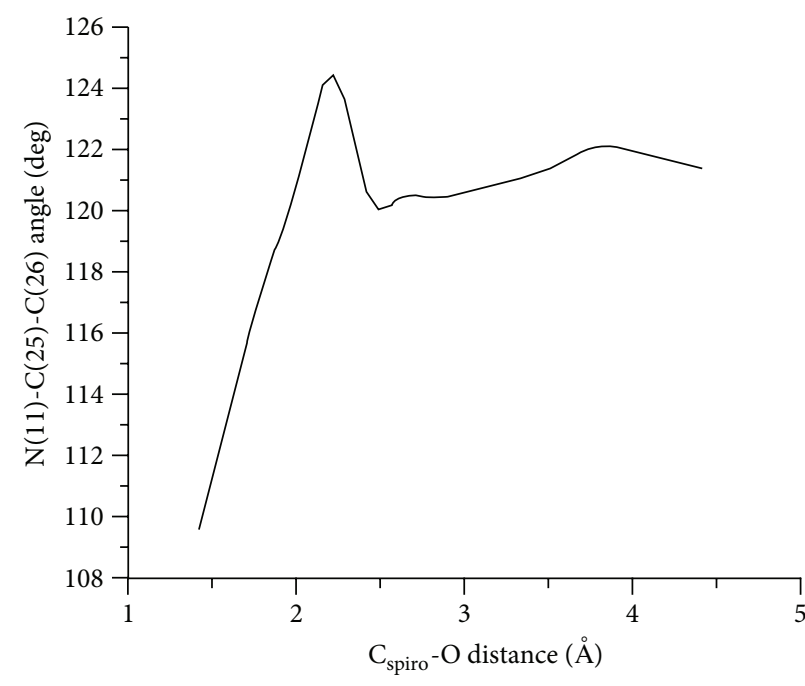

(a)

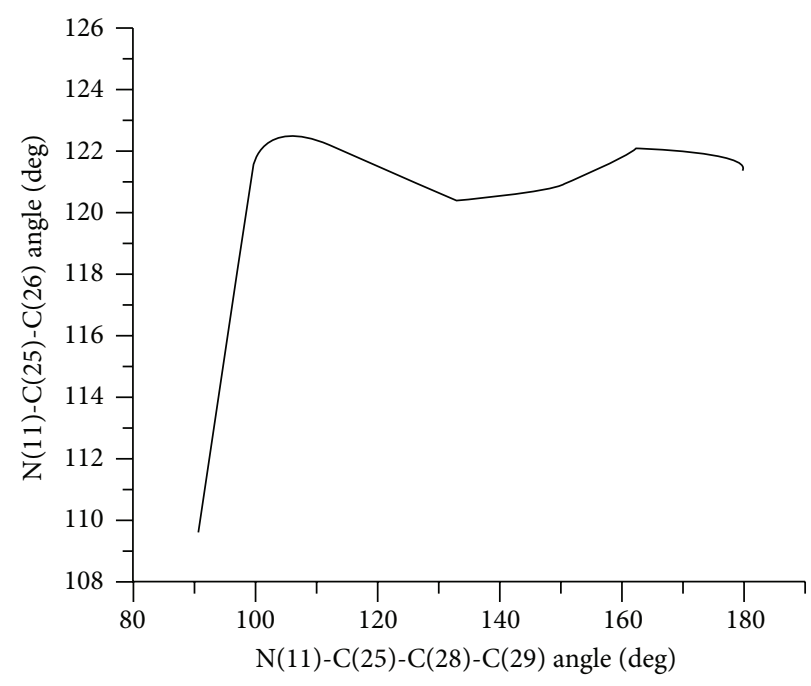

(b)

Figure 7: The dependence of the value of $\mathrm{N}(11)-\mathrm{C}(25)-\mathrm{C}(26)$ angle from the length of $\mathrm{C}_{\text {spiro }}$-O bond (a) and from dihedral angle $\mathrm{N}(11)-\mathrm{C}(25)$ $\mathrm{C}(28)-\mathrm{C}(29)$ (b).

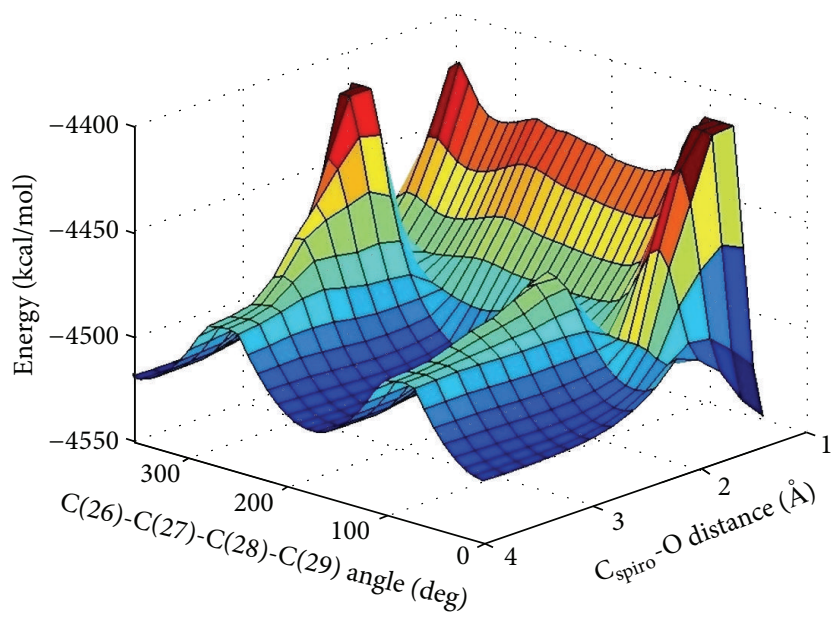

FIGURE 8: The 3D diagram of the potential surface of the spiropyran.

geodesic lines (Figure 9) that allows you to see the equilibrium states of both the merocyanine and the spiropyran. Also, it has been found that there is a very narrow corridor for the ring-closing reaction from the merocyanine to the spiropyran.

\section{Conclusions}

On the basis of the obtained results during the quantumchemical studies of conformational transformations from the merocyanine molecule to the spiropyran the following conclusions were made.

(1) Transformation from the spiropyran molecule to the merocyanine takes place by the cleavage of the

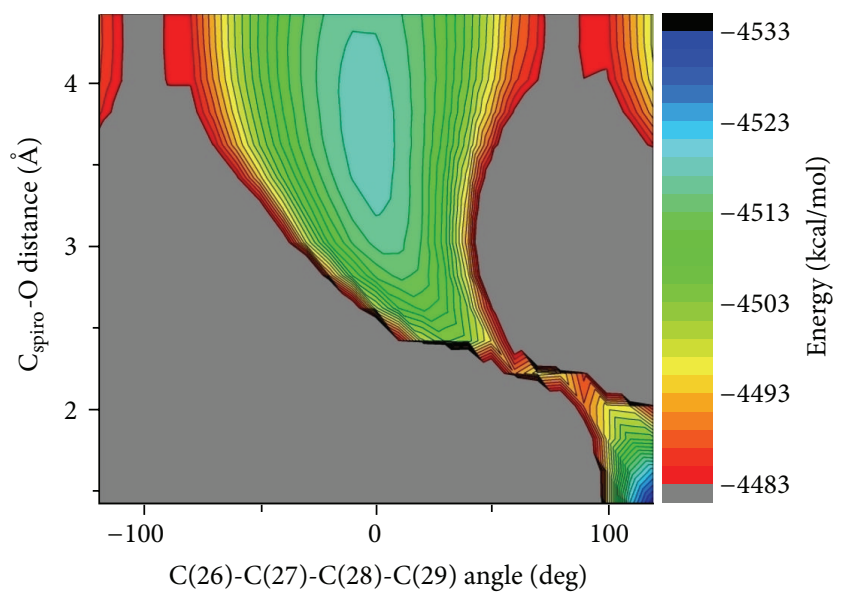

FIGURE 9: The same result is presented as in Figure 8 but in the form of geodesic lines and, in addition, the energy scale is limited by the interval of $50 \mathrm{kcal} / \mathrm{mol}$.

$\mathrm{C}_{\text {spiro }}-\mathrm{O}$ bond with its extension to $2.22 \AA$. At the same time the value of the energetic barrier before the cleavage of the bond is $1.8 \mathrm{eV}$ and for the reverse process is $-1 \mathrm{eV}$.

(2) In the presence of the cleavage of the $\mathrm{C}_{\text {spiro }}-\mathrm{O}$ bond the process of rehybridization from $\mathrm{sp}^{3}$ to $\mathrm{sp}^{2}$ of nuclear orbitals of carbon occurred.

(3) Transformation from the merocyanine molecule to the spiropyran in the ground state (thermal transformation) is performed by the simultaneous rotation of the fragments of the molecule around $\mathrm{C}(25)-\mathrm{C}(26)$, $\mathrm{C}(26)-\mathrm{C}(27)$ bonds and rehybridization from $\mathrm{sp}^{3}$ to $\mathrm{sp}^{2}$ of nuclear orbitals of carbon $\mathrm{C}_{\text {spiro }}$. 


\section{Conflict of Interests}

The authors declare that there is no conflict of interests regarding the publication of this paper.

\section{References}

[1] M. I. Zakharova, V. Pimienta, A. V. Metelitsa, V. I. Minkin, and Z.-K. Misho, "Kinetic and thermodynamic analysis of complexing metal ions with merocyanines of photochromic spiropyrans," Russian Chemical Journal, vol. 51, no. 6, pp. 71-81, 2007.

[2] I. M. Raskita, Synthesis, photochromic properties and complexation of hetaryl-substituted indoline spiropyrans [Ph.D. thesis], 2007.

[3] W. R. Browne and B. L. Feringa, "Light switching of molecules on surfaces," Annual Review of Physical Chemistry, vol. 60, pp. 407-428, 2009.

[4] M. Heilemann, P. Dedecker, J. Hofkens, and M. Sauer, "Photoswitches: Key molecules for subdiffraction-resolution fluorescence imaging and molecular quantification," Laser and Photonics Reviews, vol. 3, no. 1-2, pp. 180-202, 2009.

[5] B. L. Feringa, Molecular Switches, Wiley, Weinheim, Germany, 2001.

[6] A. V. Metelitsa, Spectrokinetics and dynamics of the photoinitiated processes in the photochromic spirocyclic systems [Ph.D. thesis], Institute of Physical and Organic Chemistry, Southern Federal University, 2012.

[7] E. Fischer and Y. Hirshberg, "Formation of coloured form of spirans by low-temperature irradiation," Journal of the Chemical Society, vol. 11, pp. 4522-4524, 1952.

[8] D. A. Reeves and F. Wilkinson, "Photochromism of spiropyrans. Part 1. Mechanism of photocolouration," Journal of the Chemical Society, vol. 69, no. 9, pp. 1381-1390, 1973.

[9] K. N. Khalanskiy, M. B. Lukyanova, E. L. Mukhanov et al., "Synthesis, structure and photochromic properties of the indoline spiropyran[3.2-F] quinolones with different substituents in the indoline cycle," Journal of Fundamental Research, vol. 11, no. 5, pp. 1249-1253, 2012.

[10] R. Heiligman-Rim, Y. Hirshberg, and E. Fischer, "Photochromism in spiropyrans. Part IV. Evidence for the existence of several forms of the colored modification," The Journal of Physical Chemistry, vol. 66, no. 12, pp. 2465-2470, 1962.

[11] L. Mukhanov, I. V. Ozhogin, S. O. Bezugliy, and B. S. Lukyanov, "Development of the synthetic approaches to the spiropyrans with modified oxazine fragment," Modern Problems of Science and Education, vol. 6, 2012, http://www.science-education.ru/ en/106-r7639.

[12] N. A. Murugan, S. Chakrabarti, and H. Ågren, "Solvent dependence of structure, charge distribution, and absorption spectrum in the photochromic merocyanine-spiropyran pair," The Journal of Physical Chemistry B, vol. 115, no. 14, pp. 4025-4032, 2011.

[13] G. Balasubramanian, J. Schulte, F. Müller-Plathe, and M. C. Böhm, "Structural and thermochemical properties of a photoresponsive spiropyran and merocyanine pair: basis set and solvent dependence in density functional predictions," Chemical Physics Letters, vol. 554, pp. 60-66, 2012.

[14] G. Cottone, R. Noto, and G. La Manna, "Theoretical study of spiropyran-merocyanine thermal isomerization," Chemical Physics Letters, vol. 388, no. 1-3, pp. 218-222, 2004.
[15] M. Sanchez-Lozano, C. Manuel Estévez, J. Hermida-Ramón, and L. Serrano-Andres, "Ultrafast ring-opening/closing and deactivation channels for a model spiropyran-merocyanine system," Journal of Physical Chemistry A, vol. 115, no. 33, pp. 9128-9138, 2011.

[16] S. Prager, I. Burghardt, and A. Dreuw, "Ultrafast $\mathrm{C}_{\text {spiro }}-\mathrm{O}$ dissociation via a conical intersection drives spiropyran to merocyanine photoswitching," The Journal of Physical Chemistry A, vol. 118, no. 8, pp. 1339-1349, 2014.

[17] F. Liu, Y. Kurashige, T. Yanai, and K. Morokuma, "Multireference $\mathrm{ab}$ initio density matrix renormalization group (DMRG)CASSCF and DMRG-CASPT2 study on the photochromic ring opening of spiropyran," Journal of Chemical Theory and Computation, vol. 9, no. 10, pp. 4462-4469, 2013.

[18] Y. Sheng, J. Leszczynski, A. A. Garcia, R. Rosario, D. Gust, and J. Springer, "Comprehensive theoretical study of the conversion reactions of spiropyrans: substituent and solvent effects," The Journal of Physical Chemistry B, vol. 108, no. 41, pp. 16233-16243, 2004.

[19] Y. Futami, M. L. S. Chin, S. Kudoh, M. Takayanagi, and M. Nakata, "Conformations of nitro-substituted spiropyran and merocyanine studied by low-temperature matrix-isolation infrared spectroscopy and density-functional-theory calculation," Chemical Physics Letters, vol. 370, no. 3-4, pp. 460-468, 2003.

[20] G. Zhai, S. Shao, S. Wu, Y. Lei, and Y. Dou, "Detailed molecular dynamics of the photochromic reaction of spiropyran: a semiclassical dynamics study," International Journal of Photoenergy, vol. 2014, Article ID 541791, 9 pages, 2014.

[21] I. Gómez, M. Reguero, and M. A. Robb, "Efficient photochemical merocyanine-to-spiropyran ring closure mechanism through an extended conical intersection seam. A model CASSCF/CASPT2 study," The Journal of Physical Chemistry A, vol. 110, no. 11, pp. 3986-3991, 2006.

[22] K. Matczyszyn, J. Olesiak-Banska, K. Nakatani et al., "One- and two-photon absorption of a spiropyran-merocyanine system: experimental and theoretical studies," Journal of Physical Chemistry B, vol. 119, no. 4, pp. 1515-1522, 2015.

[23] R. Nordin, A. M. Lazim, A. Rohadi, and S. A. Hasbullah, "Preparation and activation of spiropyran-merocyanine system," Malaysian Journal of Analytical Sciences, vol. 17, no. 3, pp. 422-429, 2013.

[24] K. K. Kalninsh, "Considerations of elementary stages in thermal reactions," Chemical Physics Letters, vol. 79, no. 3, pp. 427-430, 1981.

[25] T. Bercovici and E. Fischer, "Photosensitized coloration of photochromic spiropyrans," Journal of the American Chemical Society, vol. 86, no. 24, pp. 5687-5688, 1964.

[26] N. W. Tyer Jr. and R. S. Becker, "Photochromic spiropyrans. I. Absorption spectra and evaluation of the pi.-electron orthogonality of the constituent halves," Journal of the American Chemical Society, vol. 92, no. 5, pp. 1289-1294, 1970.

[27] K. K. Kalninsh, "The structure and thermochromism of spiropyrans. A triplet mechanism of thermoopening/closures of the pyran ring," Journal of Structural Chemistry, vol. 36, no. 5, pp. 787-797, 1998.

[28] S. M. Aldoshin, "Spyropirans. Features of the structure and photochemical properties," Uspekhi Khimiyi, vol. 59, no. 7, pp. 1144-1178, 1990.

[29] F. Jensen, Introduction to Computational Chemistry, John Wiley \& Sons, Chichester, UK, 2nd edition, 2007. 
[30] M. J. S. Dewar, E. G. Zoebisch, E. F. Healy, and J. J. P. Stewart, "The development and use of quantum-mechanical molecularmodels .76. AM1-a new general-purpose quantummechanical molecular-model," Journal of American Chemical Society, vol. 107, no. 13, pp. 3902-3909, 1985.

[31] V. A. Blatov, Nonempirical Computational Methods in Quantum Chemistry, Samara University, Samara, Russia, 1996.

[32] V. A. Blatov, A. P. Shevchenko, and E. V. Peresipkina, SemiEmpirical Computational Methods in Quantum Chemistry, Univers-Group, Samara, Russia, 2005.

[33] K. I. Ramachandran, G. Deepa, and K. Namboori, Computational Chemistry and Molecular Modeling: Principles and Applications, Springer Science \& Business Media, 2008.

[34] J. Hobley, U. Pfeifer-Fukumura, M. Bletz, T. Asahi, H. Masuhara, and H. Fukumura, "Ultrafast photo-dynamics of a reversible photochromic spiropyran," The Journal of Physical Chemistry A, vol. 106, no. 10, pp. 2265-2270, 2002.

[35] R. D. Macuil, M. R. López, V. L. Gayou, and A. O. Díaz, "Structural analysis of spiropyran polimers using ATR spectroscopy," Journal of Physics: Conference Series, vol. 28, no. 1, pp. 139-142, 2006.

[36] V. A. Barachevskiy, G. I. Lashko, and V. A. Cehomskiy, Photochromism and Its Application, Khimia, Moscow, Russia, 1977. 

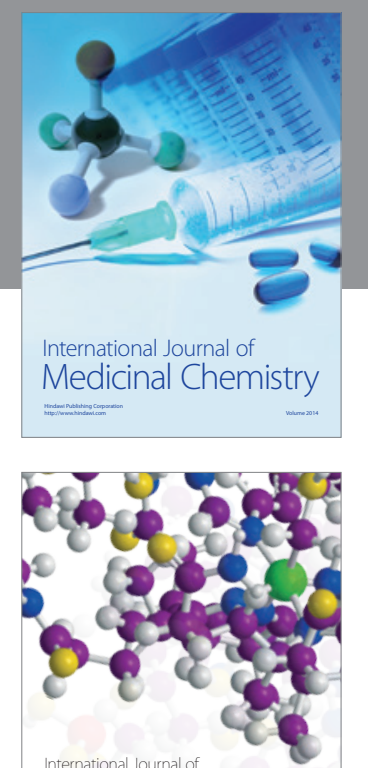

\section{Carbohydrate} Chemistry

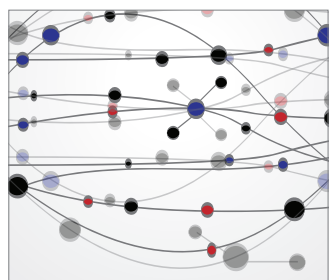

The Scientific World Journal
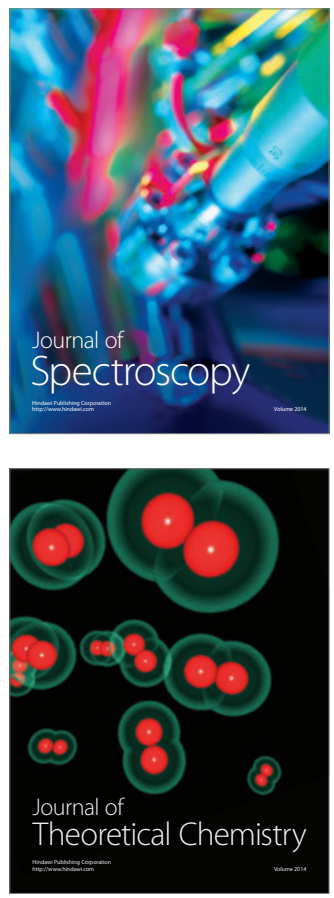
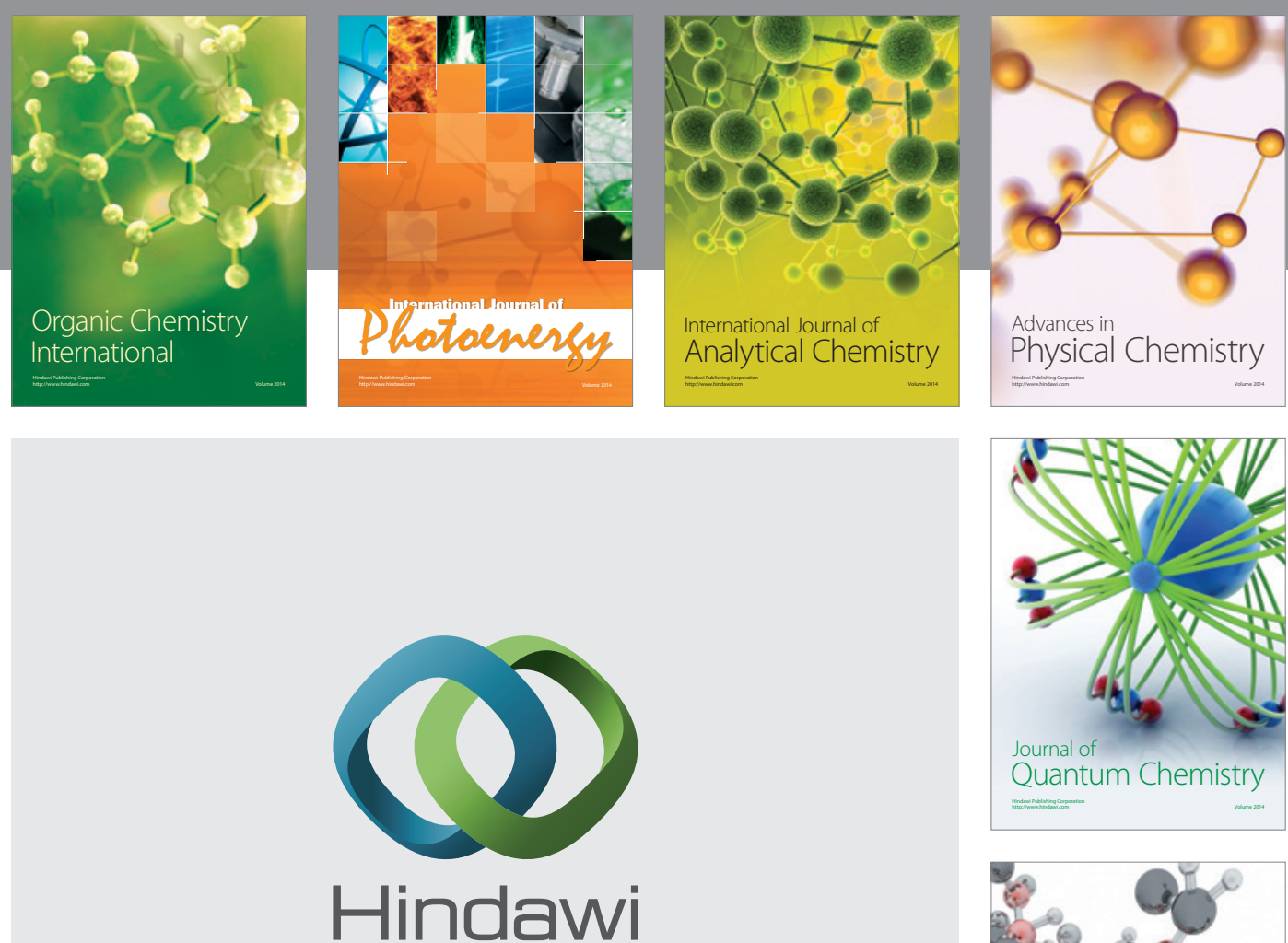

Submit your manuscripts at

http://www.hindawi.com

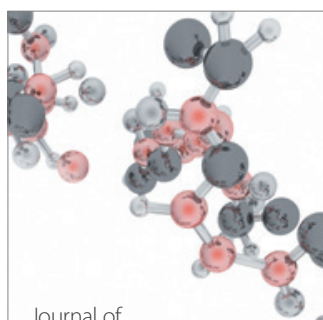

Analytical Methods

in Chemistry

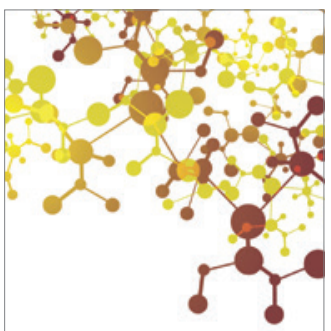

Journal of

Applied Chemistry

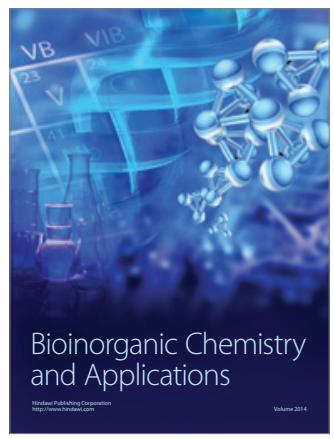

Inorganic Chemistry
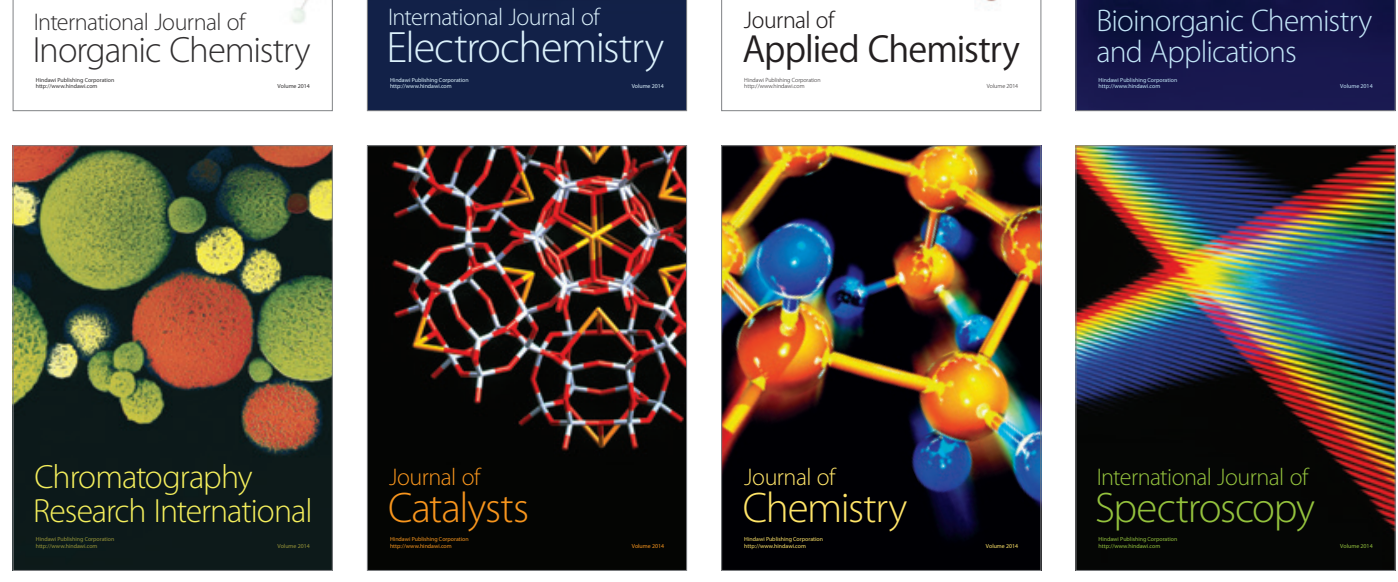